EVIDENCE BASED PUBLIC HEALTH POLICY AND PRACTICE

\title{
Screening for depleted uranium in the United Kingdom armed forces: who wants it and why?
}

\author{
Neil Greenberg, Amy C Iversen, Catherin Unwin, L Hull, S Wessely
}

J Epidemiol Community Health 2004;58:558-561. doi: 10.1136/jech.2003.014142

See end of article for authors' affiliations

Correspondence to: Dr N Greenberg, King's Centre for Military Health Research, Academic Department of Psychological Medicine, GKT School of Medicine and Institute of Psychiatry, Weston Education Centre, Cutcombe Road, London SE5 9RJ, UK; Sososanta@ aol.com

Accepted for publication 9 September 2003

\begin{abstract}
Background: Depleted uranium (DU) use has been implicated in the poor health of many service personnel who have served in the Gulf and the Balkans. Although the health related risks are thought to be small the UK government has offered to set up a voluntary screening programme for service personnel. This study aimed to find out the characteristics and possible exposures to DU for those personnel who desire DU screening.

Methods: This study looks at 2369 UK service personnel who were asked if they wanted to be screened for DU. Subjects were asked about their perceived exposure to deployment associated risks including DU and a number of psychological health measures.

Results: The study found that $24 \%$ of the cohort wanted screening, a figure that if extrapolated to all those who have been offered screening would represent 36720 requests for screening. Those who wanted DU screening were younger, of lower rank, and more likely to be from the Royal Navy or Army rather than the Royal Air Force. Those requesting DU screening reported poorer health both subjectively and as measured by the GHQ-12 and a symptom checklist. They also reported more exposure to DU and to other deployment associated risks while in military service. Using combat exposure as a proxy for a significant risk of having been exposed to DU, there was a significant correlation.

Conclusions: This study found that the desire for DU screening is more closely linked to current health status rather than plausible exposure to DU.
\end{abstract}

D epleted uranium (DU) is a toxic and weakly radioactive heavy metal used in kinetic energy weapon systems to penetrate the armour of tanks and other vehicles. It has been suggested that the use of DU munitions leads to health problems as DU can enter the body through inhalation, ingestion, or wounding. The health related risks from DU are related to both radioactive and chemical toxicity. Although studies have shown that chemical rather than radiological toxicity presents the primary concern for Gulf War veterans ${ }^{12}$ the radiological consequences of DU use have attracted a significant amount of media attention. ${ }^{3}$

As a result of the substantial discussion on the health consequences of DU use, the Royal Society (the United Kingdom's national academy of science) convened an independent expert working group to review the state of scientific knowledge about DU and concluded that, except in extreme circumstances, the cancer related risks are "so small as to not be detectable above the general risk of dying from cancer over a normal lifetime" ${ }^{\prime 4}$ The report goes on to state that "in the most extreme circumstances, such as being a survivor in a vehicle struck by a DU round and assuming the most unfavourable conditions, the lifetime risk from lung cancer is unlikely to exceed twice that in the general population". The study also found that the risks of other cancers including leukaemia are predicted to be "too small to be observable". Other studies have examined the renal and reproductive health effects associated with DU exposure and found that no detectable association exists. ${ }^{5}$

None the less, responding to continuing concern from the public, the media, and veterans, the United Kingdom Minister for the Armed Forces, Mr John Spellar, made a statement on 9 January 2001 to the effect that voluntary screening would be made available for UK service personnel to examine any possible exposure to DU for UK service personnel who had served in the Balkans. A subsequent statement on 13 February 2001 confirmed that this testing would also be available to Gulf veterans. This paper examines the characteristics of those service personnel who desire to be screened for DU.

\section{METHODS}

In 1997 a study was conducted by King's College London into the health of military personnel $(n=8195)$. The results of this study have been reported elsewhere. ${ }^{6}$ This military cohort (phase 1 sample) consisted of three groups: those personnel who served in the Gulf region between 1 September 1990 and 30 June 1991 (Gulf cohort), personnel who had served in Bosnia between 1 April 1992 and 6 February 1997 (Bosnia cohort), and personnel who were serving in the armed forces on 1 January 1991 but who were not deployed to the Gulf conflict (Era cohort). Some personnel from all three cohorts had also served in Kosovo.

A follow up study (phase 3 sample) was carried out in 2001. The primary focus of this study was to examine the health of symptomatic Gulf veterans. At phase 1, fatigue, along with being strongly associated with other health outcomes measured, was one of the most consistently reported symptoms of ill Gulf veterans. Fatigue was used as a proxy measure for being symptomatic, and the phase 1 sample was stratified according to degree of fatigue reported. To ensure that the most severely ill were well represented, the phase 3 sample included all male veterans with a fatigue score of 9 or more at phase 1 (511 Gulf, 115 Bosnia, and 120 Era) were included. A 1:2 sample of male Gulf veterans with mid-range fatigue scores of 4-8 (484 veterans) along with all Bosnia $(\mathrm{n}=333)$ and Era $(\mathrm{n}=364)$ veterans scoring in this range were selected. Finally, an approximately $1: 8$ sample of veterans with fatigue scores less than 4 was selected to represent unsymptomatic veterans (250 in each group). Additionally all female veterans who completed the phase 1

Abbreviations: DoD, US Department of Defense; DU, depleted uranium; GHQ, general health questionnaire; MOD, UK Ministry of Defence 
questionnaire $(n=648)$ were contacted, as women were over sampled in the original cohort. The total sample size was 3322 .

The phase 3 survey examined a number of issues, one of which was an inquiry as to whether the sampled service person thought they should be screened for DU.

\section{Investigations}

All subjects were asked if they thought they should be screened for DU exposure. Inquiries were also made into a number of demographic details including gender, age service, deployment history, rank (for those serving), and whether they were still serving in the armed forces or not. Those who had served in the Gulf war were also asked about their primary duties in the Gulf in particular whether they served in a combat arm (for example, infantry or tanks) or service support arm, (for example, signals, logistics, or medical).

Measurement of general health status was inquired about directly and the 12 item version of the general health questionnaire was also administered. ${ }^{7}$ Total somatic symptoms were measured by a symptom checklist. ${ }^{6}$ Subjects were also asked about their experiences in theatre particularly about their exposure to a number of potentially "risky" situations associated with deployment. There were 27 situation exposures enquired about for the Gulf cohort and 23 for personnel in the other cohorts (shown in the appendix, available on the journal web site http://www.jech.com/ supplemental). The questionnaire also inquired about whether the person had handled DU ordnance, breathed in DU dust, or entered a tank that had been hit and disabled by DU munitions. Finally subjects who had been in the Gulf were asked if they thought they had Gulf War syndrome.

\section{Analysis}

Data were entered into a SPSS (version 11) spreadsheet and analysed accordingly. The categorical data were analysed using the $\chi^{2}$ test, while continuous variables were analysed using the $t$ test.

\section{RESULTS}

There were 2369 respondents to the 3322 questionnaires sent out $(71 \%)$. Of the 2369, 2192 answered the question inquiring about DU screening, (92\%). Those who did not respond or who did respond but did not answer the question about DU screening were no older $\left(\chi^{2}=47.7, \mathrm{df}=43\right.$, $\mathrm{p}=0.29)$, no more likely to have left the military $\left(\chi^{2}=0.17, \mathrm{df}=1, \mathrm{p}=0.683\right)$, no more likely to be Royal
Navy, Army or Royal Air Force $\left(\chi^{2}=0.575, \mathrm{df}=3, \mathrm{p}=0.124\right)$, and no more likely to be from the Gulf, Bosnia, or Era cohorts $\left(\chi^{2}=4.8, \mathrm{df}=2, \mathrm{p}=0.09\right)$. The non-responders were, however, more likely to be female rather than male $\left(\chi^{2}=8.6\right.$, $\mathrm{df}=1, \mathrm{p}=0.003$ ).

Of the responders who answered the DU question, 529 $(24.4 \%)$ reported a desire for DU screening. They were significantly younger (mean age $=36.7$ years) than those who did not want screening (mean age $=38.2$ years $)(t=4.0$, $\mathrm{df}=2022, \mathrm{p}<0.001)$, and there was a significant difference by gender, a positive response given by $28 \%$ of servicemen $(\mathrm{n}=487)$ and $11 \%$ of servicewomen $(\mathrm{n}=42) \quad\left(\chi^{2}=56.6\right.$, $\mathrm{df}=1, \mathrm{p}<0.001)$.

Table 1 shows the results of the four military variablesthat is, cohort, service of armed forces, serving status (still serving or discharged), and rank (for those still serving).

As table 1 shows, the desire for DU screening was significantly higher among those who had been deployed to both the Gulf and Bosnia conflicts (44.4\%). The next highest rate was for those who had been deployed to the Gulf conflict $(34.2 \%)$ with the lowest rate being for the Era group (11\%).

There was a significant difference between the three services within the armed forces, with the Army and Royal Navy having significantly higher rates $(26 \%$ and $23 \%$ respectively) than the Royal Air Force (11\%). There was no difference in the rates between those still serving and discharged from the services ( $24.2 \%$ and $23.7 \%$ respectively). For those still in service, the officer ranks had a significantly lower rate than the NCOs and lower ranks $(13.6 \%, 27.4 \%$, and $23.5 \%$ respectively)

There was significant correlation between self reported exposure to deployment associated risk situations and the desire for DU screening for veterans of Gulf and Bosnia deployments. The original sampling strategy had examined three groups (Gulf, Bosnia, and Era). However, by the time of follow up some of all three groups had also served in Kosovo. The association between deployment associated risks and a desire for DU screening was not significant for the smaller numbers of personnel who had served in Kosovo (table 2).

When personnel were asked about their perception of their own general health, poor health was significantly associated with a desire for DU screening, $\left(\chi^{2}=114.715\right.$, df 16 , $\mathrm{p}<0.001$ ) (table 3 ). In keeping with their general perception of poorer health, those who requested DU screening had significantly higher GHQ-12 scores and reported experiencing more symptoms over the past month. Table 4 shows these data.

\begin{tabular}{|c|c|c|c|c|c|}
\hline \multicolumn{6}{|c|}{ Do you think you should be screened for depleted uranium? } \\
\hline & \multicolumn{2}{|l|}{ Yes } & \multicolumn{2}{|l|}{ No } & \multirow[b]{2}{*}{ p Value } \\
\hline & Number & (\%) & Number & (\%) & \\
\hline Cohort & & & & & $<0.01$ \\
\hline Gulf & 268 & $(34.2)$ & 516 & (65.8) & \\
\hline Bosnia & 86 & (16.4) & 437 & (83.6) & \\
\hline Era & 62 & (11.1) & 495 & (88.9) & \\
\hline Gulf and Bosnia & 72 & $(44.4)$ & 90 & $\begin{array}{l}100.71 \\
(55.6)\end{array}$ & \\
\hline Service & & & & & $<0.01$ \\
\hline Royal Navy & 26 & (22.8) & 88 & (77.2) & \\
\hline Army & 439 & $(25.9)$ & 1254 & (74.1) & \\
\hline Royal Air Force & 23 & (10.5) & 196 & (89.5) & \\
\hline Serving status & & & & & 0.81 \\
\hline Discharged & 262 & (24.2) & 822 & (75.8) & \\
\hline Still in service & 214 & $(23.7)$ & 689 & (76.3) & \\
\hline Rank (still in service) & & & & & $<0.01$ \\
\hline Other & 12 & (23.5) & 39 & (76.5) & \\
\hline NCO & 177 & (27.4) & 469 & (72.6) & \\
\hline Officer & 28 & $(13.6)$ & 178 & (86.4) & \\
\hline
\end{tabular}


Table 2 Risk exposure perception in relation to the desire for depleted uranium screening

Do you think you should be screened for depleted uranium?

\begin{tabular}{|c|c|c|c|c|c|}
\hline & \multicolumn{2}{|l|}{ Yes } & \multicolumn{2}{|l|}{ No } & \multirow[b]{2}{*}{ Statistics } \\
\hline & Mean $(\mathbf{n})$ & SD & Mean (n) & SD & \\
\hline $\begin{array}{l}\text { Bosnia risks } \\
\text { Gulf risks } \\
\text { Kosovo risks }\end{array}$ & $\begin{array}{l}9.3(n=156) \\
14.3(n=356) \\
7.2(n=89)\end{array}$ & $\begin{array}{l}3.9 \\
4.3 \\
4.0\end{array}$ & $\begin{array}{l}8.2(n=478) \\
10.1(n=566) \\
6.6(n=163)\end{array}$ & $\begin{array}{l}4.0 \\
4.4 \\
3.8\end{array}$ & $\begin{array}{l}p=0.002, t=3.1, d f=632 \\
p<0.001, t=14.1, d f=920 \\
p=0.32, t=0.997, d f=250\end{array}$ \\
\hline
\end{tabular}

Table 3 Health perceptions and the desire for depleted uranium screening

Do you think you should be screened for depleted uranium exposure?

\begin{tabular}{llll}
\hline Health rating (self report) & $\begin{array}{l}\text { Yes } \\
\text { Number (\%) }\end{array}$ & $\begin{array}{l}\text { No } \\
\text { Number (\%) }\end{array}$ & Total \\
\hline Excellent & $56(13)$ & $354(87)$ & $410(100)$ \\
Very good & $134(18)$ & $591(82)$ & $727(100)$ \\
Good & $124(27)$ & $338(73)$ & $462(100)$ \\
Fair & $152(36)$ & $267(64)$ & $419(100)$ \\
Poor & $52(49)$ & $54(51)$ & $106(100)$ \\
Total & 518 & 1605 & 2123 \\
\hline
\end{tabular}

The belief that you were suffering with Gulf War syndrome was also significantly associated with wanting DU screening $\left(\chi^{2}=110.6, \mathrm{df}=3, \mathrm{p}<0.001\right)$.

Those who reported coming into close contact with DU material were more likely to request screening, specifically those who had ever handled DU ordnance $\left(\chi^{2} 303, \mathrm{df}=6\right.$, $\mathrm{p}<0.001)$, those who reported having breathed in DU dust $\left(\chi^{2}=373, \mathrm{df}=4, \mathrm{p}<0.001\right)$ and those who reported having entered tanks hit and disabled by DU munitions $\left(\chi^{2}=1518\right.$, $\mathrm{df}=4, \mathrm{p}<0.001)$. Interestingly $13 \%$ of those who reported breathing in DU dust and $28 \%$ of those who reported entering tanks knocked out by DU munitions did not request DU screening.

During the first phase of the study (1997/1998) veterans were asked about their primary duties in the Gulf. Those who reported combat as their primary duty $(18 \%, \mathrm{n}=166)$ in the Gulf were significantly more likely to request DU screening $\left(\chi^{2}=35.4, \mathrm{df}=1, \mathrm{p}<0.001\right)$.

\section{DISCUSSION}

\section{Main findings}

This study found that $24 \%(n=529)$ of our sample indicated they would like to be screened for DU. If one extrapolated this figure to all those who served in the Gulf War (53 000), then 12720 service personnel will want DU screening. If one includes the personnel who have deployed to the Balkans (about 100 000) an additional 24000 may want screening. If all 36720 of those who desire DU screening take up the offer that has been made by the government (it is not known whether they will) there is going to be a substantial cost to the public purse and no doubt there will also be some further calls on the already overstretched defence medical services.

The current data from the King's follow up survey suggest that those who think they should be screened for DU are likely to be younger servicemen, and from the Royal Navy and Army as compared with the Royal Air Force. They are more likely to have served in the Gulf or Bosnia, with the rates being highest for those who had deployed to both. They are as likely to be still serving as discharged, and for those who are still in service, are likely to be of the lower ranks.

Additionally they report poorer self perceived general health, worse psychological health, and more somatic symptoms. In keeping with their risk for screening, they perceive themselves to have been exposed to more DU risk associated situations, although even in the group who thought that they had breathed in DU dust, some 13\% did not want to be screened. For those in Bosnia and the Gulf, the more exposure they reported to deployment related risks the more likely they were to want screening. The same trend was observed for those deployed to Kosovo, although the small sample size may have lacked the power to show a true association. It therefore seems clear that for many service personnel the desire for DU screening is linked to a poor perception of general health and feeling of having been exposed to a large amount of risk related situations.

For those deployed to the Gulf, those who served in a combat arm, and those who thought they were suffering from Gulf War syndrome were more likely to want screening.

\section{Limitations of the study}

The study sample was weighted to make up a sample that was over representative of fatigued personnel and thus the

\begin{tabular}{|c|c|c|c|c|c|}
\hline \multicolumn{6}{|c|}{ Do you think you should be screened for depleted uranium? } \\
\hline \multirow[b]{2}{*}{ Question } & \multicolumn{2}{|l|}{ Yes } & \multicolumn{2}{|l|}{ No } & \multirow[b]{2}{*}{ Statistics } \\
\hline & Mean & SD & Mean & SD & \\
\hline GHQ score & 17.2 & 7.1 & 14.0 & 6.2 & $p<0.001, t=9.8, d f=2077$ \\
\hline Overall symptom score & 17.0 & 11.0 & 9.4 & 8.0 & $\mathrm{p}<0.001, t=17.1, d f=2168$ \\
\hline
\end{tabular}




\section{Key points}

- The desire for DU screening is primarily determined by current health status rather than a proxy measure of risk of exposure.

- Those who desire DU screened recount more DU exposure and to other deployment associated risks, but this is by retrospective self report.

- The most objective marker of true DU exposure that we have available uses combat exposure as a proxy in Gulf War veterans and this proxy measure suggest that there is a link between the risk of exposure to DU and a desire for screening.

- It is clear from this study that any screening programme that is established will have to deal with large numbers of service personnel who have a low risk of DU exposure

- It would seem prudent to reassess the wisdom of offering DU screening to a large number of personnel at low risk of ever having been exposed to DU.

overall levels of psychopathology generally are likely to be higher than is found in a random sample of military population. However, this would not explain the significant variations, between those that desired DU screening or not, that have been found in this study. Of note is that women were significantly over represented in the non-responder group. However, female responders were significantly less likely to desire DU screening and therefore is seems unlikely that the non-responder group was composed of significantly more personnel who did in fact desire screening. Additionally in the UK armed forces, women are very unlikely to be engaged in combat duties and thus are less likely to have been in situations where exposure to DU was possible.

This study relies on recall of information from many years ago and is therefore likely to be subject to recall bias. This is of particular relevance to the desire for DU screening as it seems that current symptoms (as measured by the GHQ-12 and the symptom checklist) are an important determinant in the desire for DU screening. It is possible that current mental state will have influenced recall of exposure to both deployment associated risk situations and exposure to situations associated with DU. This sort of recall bias has been found in previous studies involving Gulf War veterans. ${ }^{8}{ }^{9}$ Additionally, to determine combat status within the Gulf War, we asked about the service person's primary duty. As the questionnaire was sent out some seven or so years after the war, it is likely that recall of primary duty in the Gulf will have also been subject to bias. None the less, the recall of primary duty is likely to be a considerably more objective measure than the recall of exposure to risky situations. It may have been preferable to try and link the service person with their unit's known duties during the war. However, given that the ground war lasted only 100 hours and that many personnel were temporarily detached from their parent unit during the war, this exercise would still not give the "true" picture of possible risk of exposure to DU.

\section{Conclusion}

This study shows that the desire for DU screening is primarily determined by current health status rather than a proxy measure of risk of exposure. Those who desire DU screening recount more DU exposure, but this is by retrospective self report. Additionally they report more exposure to other deployment associated risk situations. The most objective

\section{Policy implications}

- The UK government should strongly consider whether offering DU screening for service personnel is an effective use of public funds.

- If an effective DU screening is made available, those performing the screening should be prepared to work with a group in which the majority of those requesting screening will come from a low exposure risk group

- This paper questions whether open ended screening of UK military personnel for DU is cost effective

marker of true DU exposure that we have available uses combat exposure as a proxy. This is, however, limited to those who are Gulf War veterans. Using this proxy measure suggests that there is a link between the risk of exposure to DU and a desire for screening. Nevertheless it is clear from this study that any screening programme that is established will have to deal with large numbers of service personnel who have a low risk of DU exposure. Other long term follow up studies have found no substantial link to the development of cancer or other adverse physical health outcomes either in miners who have had occupational exposure to uranium ( $160 \%$ more radioactive than DU) or in US military personnel who have DU fragments imbedded in their body. As such it would seem prudent to reassess the wisdom of offering DU screening to a large number of personnel at low risk of ever having been exposed to DU.

\section{ACKNOWLEDGEMENTS}

We thank Mr Nick Blatchley of MOD for help in identifying the cohorts used in this study.

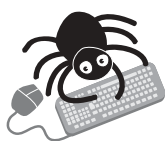

The appendix is available to view on the journal web site (http://www.jech.com/supplemental)

\section{Authors' affiliations}

N Greenberg, A C Iversen, C Unwin, L Hull, S Wessely, Department of Psychological Medicine, New Medical School, King's College Hospital, London, UK

The stage 1 study was funded by the US Department of Defense (DoD) and the follow up study by the Medical Research Counsel (MRC). Neither the DoD nor MRC had any input into the design, conduct, analysis, or reporting of the study. The views expressed are not those of any US or UK governmental organisation.

\section{REFERENCES}

1 Agency for Toxic Substances and Disease Registry. Toxicological profile for uranium. Washington, DC: US Public Health Service, 1999.

2 Kathren RL, Mclnroy JF, Moore RH, et al. Uranium in the tissues of an occupationally-exposed individual. Health Phys 1989;57:17-21.

3 Norton-Taylor R, Osborn A. Gulf veterans left in cold. Balkans troops to be screened for uranium. Guardian, 2001;10 Jan.

4 The Royal Society. The health hazards of depleted uranium munitions: part one. Policy document 6/01. Royal Society: London, 2001.

5 McDiarmid MA, Squibb K, Engelhardt S, et al. Surveillance of depleted uranium exposed Gulf War veterans: health effects observed in an enlarged "friendly fire" cohort. J Occup Environ Med 2001;43:991-1000.

6 Unwin C, Blatchley N, Coker W, et al. The health of United Kingdom servicemen who served in the Persian Gulf War. Lancet 1999;353:169-78.

7 Goldberg $\mathrm{D}$. The detection of psychiatric illness by questionnaire. London: Oxford University Press, 1972.

8 McCauley L, Joos S, Spencer P, et al. Strategies to assess validity of self reported exposures during the Persian Gulf War. Environ Res 1999;81:195-205.

9 Wessely S, Unwin C, Hull L, et al. Is the recall of military hazards stable over time? Evidence from the Gulf War. Br J Psychiatry 2003;183:314-22. 